\title{
RANCANG BANGUN TEROWONGAN ANGIN (WIND TUNNEL) TIPE SUBSONIC DENGAN TEST SECTION 0,2 X 0,2 M UNTUK ALAT PERAGA MEKANIKA FLUIDA
}

\author{
Imam Maulana Idris \\ 1,2Teknik Mesin, Fakultas Teknik \\ Universitas Maarif Hasyim Latif, Sidoarjo, Indonesia \\ e-mail : imam-maulana-idris@student.umaha.ac.id
}

\begin{abstract}
ABSTRAK
Wind tunnel merupakan suatu alat yang berfungsi untuk mengetahui suatu kondisi udara yang mengenai benda padat. wind tunnel sering digunakan dalam berbagai bidang seperti aerodinamika, teknik, dan fisika, melalui bidang bidang tersebut terowongan angin memegang peranan penting. Karena di labolatorium teknik mesin belum mempunyai wind tunnel, padahal peranannya sangat dibutuhkan untuk penelitian mahasiswa. Tujuan yang ingin di capai dalam rancang bangun ini adalah sebagai alat penunjang praktikum di labolatorium Universitas Ma'arif Hasyim Latief dalam bidang ilmu aerodinamika ataupun dalam perkembangan dunia otomotif dengan menyesuaikan dengan wind tunnel yang sudah pernah dibuat dan memenuhi standart. Rancang bangun ini menghasilkan wind tunnel tipe subsonic dengan test section $0,2 \times 0,2 \mathrm{~m}$ yang mempunyai ukuran keseluruan $2,42 \mathrm{~m} \mathrm{X} \mathrm{0,61m} \mathrm{X} \mathrm{1,11m,} \mathrm{dengan} \mathrm{panjang} \mathrm{Test}$ Section $0,452 \mathrm{~m}$, Diffuser $0,909 \mathrm{~m}$, Contraction $0,508 \mathrm{~m}$, Hanycome $0,096 \mathrm{~m}$, dan wind tunnel yang telah dibuat dapat bekerja dengan baik.
\end{abstract}

Kata kunci: Aerodinamika, Rancang Bangun, Subsonic, Terowongan angin, Test Section, Wind Tunnel.

\section{PENDAHULUAN}

Terowongan angin atau wind tunnel sering digunakan dalam berbagai bidang seperti aerodinamika, teknik, dan fisika, melalui bidang bidang tersebut terowongan angin memegang peranan penting dalam kehidupan manusia contohnya desain pesawat terbang dan bodi mobil dengan adanya terowongan angin ini yang fungsinya untuk mensimulasi sebuah kondisi udara terhadap suatu model.

Dengan begitu peranan terowongan angin sangatlah penting di labolatorium teknik mesin, dengan berdirinya labolatorium teknik mesin di Universitas Ma'arif Hasyim Latief (UMAHA) Sidoarjo yang setahap demi setahap melengkapi peralatan penunjang untuk praktikum mahasiswa, Karena di labolatorium teknik mesin belum ada wind tunnel, padahal peranannya sangat di butuhkan untuk penelitian mahasiswa oleh karena itu dalam tugas akhir ini penulis membuat sebual alat yaitu wind tunnel. dengan maksud untuk mendukung peneltian di bidang aerodinamika dan melengkapi peralatan penunjang untuk praktikum di labolatorium UMAHA.

Maka dari itu pengetahuan dan pemahaman mengenai pengaplikasinya alat tersebut sangat diperlukan oleh mahasiswa teknik, khususnya mahasiswa jurusan teknik mesin. Alat ini dapat digunakan untuk mempermudah pemahaman para mahasiswa mengenai hal-hal di atas tersebut. Di mana diharapkan alat ini dapat lebih bermanfaat untuk mahasiswa teknik yang akan melakukan penelitian aerodinamik untuk mempelajari efek udara yang bergerak melewati benda padat

\section{METODE PENELITIAN}

Perancangan Merupakan proses awal kegiatan dari usaha mewujudkan suatu produk yang dibutuhkan labolatorium dan kelas proyek untuk mempermudah mempelajari mata kuliah mekanika fliuda atau lebih tepatnya alat peraga mekanika fluida. Setelah perancangan selesai suatu produk telah selesai diteruskan kegiatan selanjutnya adalah pembuatan produk.

Perancangan itu sendiri terdiri dari serangkaian kegiatan yang berurutan yaitu identifikasi suatu masalah dari kebutuhan labolatorium teknik mesin dan kelas proyek hingga penyelesaiannya 


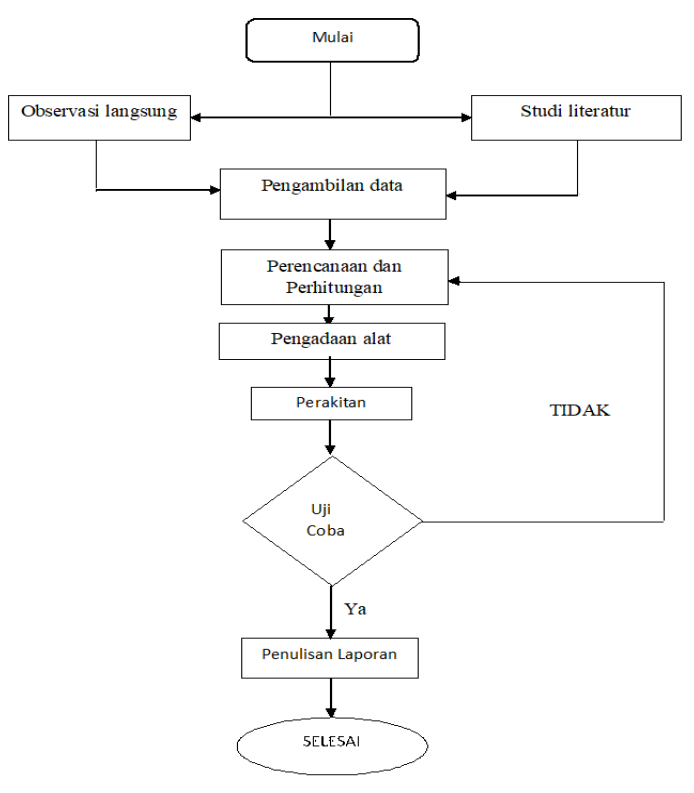

Gambar 1 Diagram alir penelitian

\section{Bahan dan Alat}

Bahan:
a. Plat aluminium
b. Motor
c. Fan
d. Besi siku
e. Mur dan baut
f. Screen
g. Hanycome

Alat-alat:
a. Gerinda
b. Bor
c. Las TIG
d. Roll meter

\section{Tempat dan Waktu}

Pembutan alat ini dilakukan selama 2 bulan di labolatorium UMAHA yang dimulai dari perancangan, pembuatan, hingga tahap uji coba alat.

\section{PERHITUNGAN DAN PEMBAHASAN}

Pembuatan terowongan angin yang terdiri dari beberapa bagian yaitu settling chamber atau bisa disebut juga ruang penenang yang berfungsi untuk mengurangi turbolensi aliran di dalam terowongan didalam bagian ini deletakkan hanycome dan screen, Diffuser adalah salah satu ruang pada wind tunnel yang memilik luas penampang yang perlahan-lahan melebar. Diffuser berfungsi sebagai komponen yang menyebabkan kenaikan tekanan pada udara. Ketika udara melalui diffuser maka tekanannya akan naik, tetapi kecepatannya menurun, sesuai dengan Prinsip Bernoulli menyatakan bahwa pada suatu aliran fluida,
Peningkatan kecepatan pada fluida kan menimbulkan penurunan tekanan pada aliran tersebut, atau sebaliknya. Contrction adalah ruang yang memiliki luas perlahan lahan mengecil bagian ini memiliki fungsi yang berlawanan dari diffuser, Test section adalah bagian terowongan angin untuk meletakkan model atau benda yang akan di uji. Terowongan angin ini mempunyai ukuran keseluruan 2,42m X 1,11m X 0,61m. berikut penjelasan lebih lanjut.

\section{Perhitungan panjang test section} $\mathrm{L}_{\mathrm{s}}=2 \cdot \mathrm{Dh}_{\mathrm{h}}$ Panjang test section dapat dicari dengan rumus

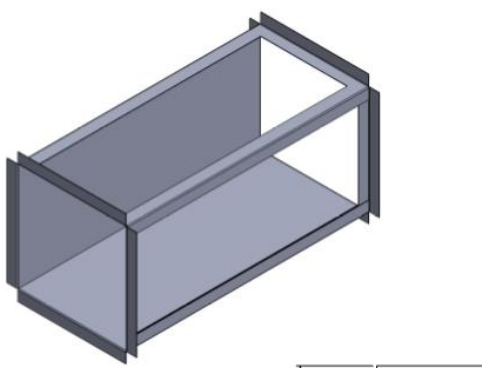

Gambar 2 test section

Dimana $\mathrm{D}_{\mathrm{h}}=$ diameter hidraulik

$$
D h=\sqrt[2]{\frac{A}{\pi}}
$$

Diameter hidraulik dapat dicari dengan rumus

$$
A=\pi \frac{D h^{2}}{4}
$$

Dimana A direncanakan 0,2 $\mathrm{m}$

$A=0,2 \mathrm{~m} \cdot 0,2 \mathrm{~m}=0,04 \mathrm{~m}^{2}$

$4 \mathrm{~A}=. \mathrm{D}_{\mathrm{h}}^{2}$

$\mathrm{D}_{\mathrm{h}}^{2}=\sqrt{\frac{4 \cdot A}{\pi}}=0,226 \mathrm{~m}^{2}$

$\mathrm{L}_{\mathrm{s}}=2 \cdot 0,226 \mathrm{~m}^{2}=0,452 \mathrm{~m}^{2}$

Jadi panjang test section ( $\mathrm{L}_{s}$ ) adalah $0,452 \mathrm{~m}^{2}$

\section{Perhitungan panjang diffuser}

Untuk mencari panjang diffuser diharusakan mengetahui diameter fan.

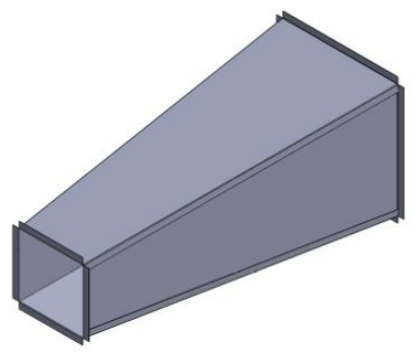

Gambar 3 diffuser 
Fan area 2 sampai 3 kali test section, untuk itu diambil 2 kali test section.

Fan area $=\mathrm{A} \cdot 2=0,08 \mathrm{~m}^{2}$

$$
F A=\frac{\pi}{4} \cdot \mathrm{D}^{2}
$$

$0,08 \mathrm{~m}^{2}=\frac{\pi}{4} \cdot \mathrm{Dh}^{2}$

$\frac{4 \cdot 0,08 m 2}{\pi}=\mathrm{Dh}^{2}$

$\mathrm{D}_{\mathrm{f}}=\sqrt{0,1018}=0,3191 \mathrm{~m}^{2}$

Jadi diameter fan adalah $0,3191 \mathrm{~m}^{2}$

$0,3191 \mathrm{~m}=13$ inch

Dikarenakan sulit mencari fan 13 inch maka dari itu digunaan fan 14 inch

14 inch $=0,36 \mathrm{~m}$

$\mathrm{FAr}=2 . \mathrm{Df}=0,1296 \mathrm{~m}^{2}$

$$
A r \frac{F A r}{A}=\frac{0,1296 m 2}{0,04 m 2} 3,24
$$

$\theta=2 . \alpha$

$$
\begin{aligned}
\mathrm{L}_{d} & =R 1\left(\frac{A r^{\frac{1}{2}}-1}{\tan \theta}\right) \\
& =0,2\left(\frac{3,24^{\frac{1}{2}}-1}{\tan 10^{\circ}}\right) \\
& =0,2(4,545) \\
& =0,909 \mathrm{~m}
\end{aligned}
$$

Jadi panjang diffuser adalah 0,909 m

\section{Perhitungan panjnang Contraction}

Contraction area berdimensi antara 6 sampai 10 kali luas test section, untuk itu diambil 8 kali luas test section.

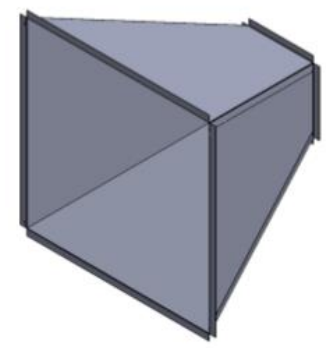

Gambar 4 contraction

$\mathrm{C}_{\mathrm{a}}=\mathrm{A} \cdot 8=0,32 \mathrm{~m}^{2}$

H contraction $=\sqrt{0,32}$

$$
=0,565 \mathrm{~m}^{2}
$$

$$
\begin{aligned}
\mathrm{y} & =\mathrm{a} \xi^{5}+\mathrm{b} \xi^{4}+\mathrm{c} \xi^{3}+\mathrm{d} \xi^{2}+\mathrm{e} \xi+\mathrm{f} \\
\xi & =\frac{x}{L} \text { dan } \mathrm{y}=\mathrm{h} \text { dan } 0 \leq \mathrm{X} \leq \mathrm{L} \\
\xi & =0 \rightarrow \mathrm{y}=\mathrm{y}_{0} \\
\xi & =1 \rightarrow \mathrm{y}=\mathrm{y} 1 \\
\xi & =0 \rightarrow \frac{d y}{d \xi}=0 \\
\xi & =1 \rightarrow \frac{d y}{d \xi}=0 \\
\xi & =0 \rightarrow \frac{d^{2} y}{d \xi^{2}}=0 \\
\xi & =1 \rightarrow \frac{d^{2} y}{d \xi^{2}}=0 \\
\frac{L n}{2 y 0} & =1 \\
\frac{L n}{2 y 0} & =0.9 \\
\operatorname{Ln} & =2 \mathrm{y}^{0} .0,9 \\
& =0,565 \mathrm{~m}^{2} \cdot 0,9 \\
& =0,5085 \mathrm{~m}^{2}
\end{aligned}
$$

Jadi panjang contraction adalah $0,5085 \mathrm{~m}^{2}$

\section{Perhitungan panjang Hanycome}

Panjang hanycome dapat dicari dengan rumus $L h=D . F C$

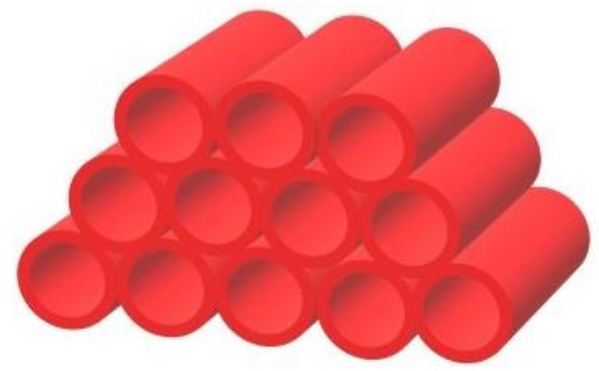

Gambar 5 hanycome

Dimana diketahui

$\mathrm{D}=0,012 \mathrm{~m}$

$\mathrm{Fc}=$ factor koreksi 6 sampai 8 kali, dipilih 8 kali

$\mathrm{L}_{\mathrm{h}}=\mathrm{D} .8$

$=0,012 \mathrm{~m} \cdot 8=0,096 \mathrm{~m}$

Jadi panjang hanycome adalah 0,096 m

\section{Proses pembuatan}

Dalam pembuatan wind tunnel ini melalui beberapa proses yaitu sebagai berikut :

a. Setelah semua bahan sudah tersedia dilakukan pemotongan plat aluminium sesuai gambar desain pada setiap bagian bagian wind tunnel yang sudah dibuat.

b. Setelah proses pemotongan pada setiap bagian bagian wind tunnel sudah selesai tahap selanjutnya adalah dilakukan proses menggunakan metal bending machine untuk mendapatkan bentuk yang sesuai dengan desain. 

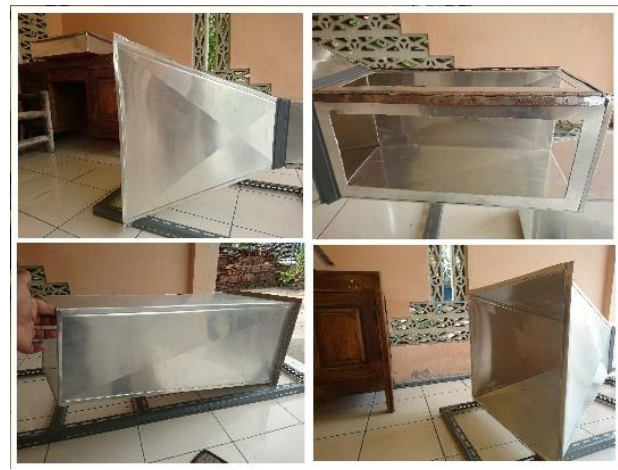

Gambar 6 Bagian wind tunnel setelah proses bending

c. Setelah proses menggunakan metal bending machine selesai untuk bagian test section diberi lubang berbentuk persegi panjang dibagian atas dan samping dengan dimensi $0,15 \quad \mathrm{x} \quad 0,45 \mathrm{~m}$ untuk menempatkan akrilik.

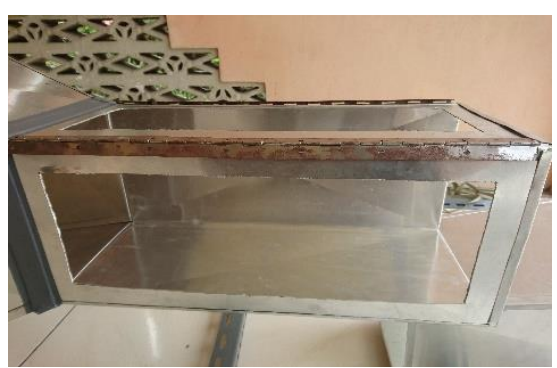

Gambar 7 Lubang pada test section

d. Proses selnjutnya adalah pemasangan hanycome pada bagian settling chamber yang berdimensi 0,57 x 0,57 $\mathrm{m}$, pemasangan ini dilakukan secara keseluruhan atau sampai full memenuhi bagian dalam settling chamber

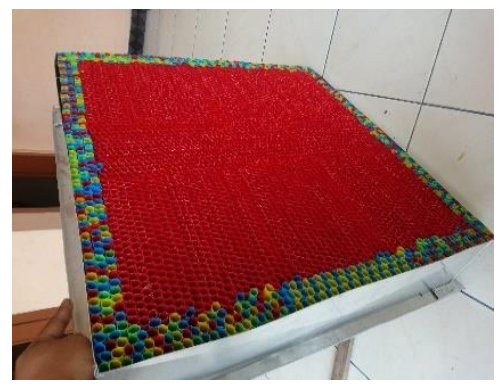

Gambar 8 Pemasangan hanycome

e. Setelah pemasangan hanycome, dibagian settling chamber ini juga dilakukan pemasangan screen yang di letakkan di bagian depan hanycome.

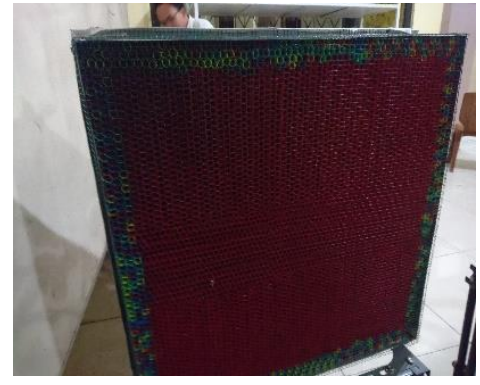

Gambar 9 Pemasangan screen

f. Selanjutnya adalah pembuatan kaki kaki penyangga wind tunnel dengan menggunakan besi siku lubang dengan ketinggian $0,50 \mathrm{~m}$.

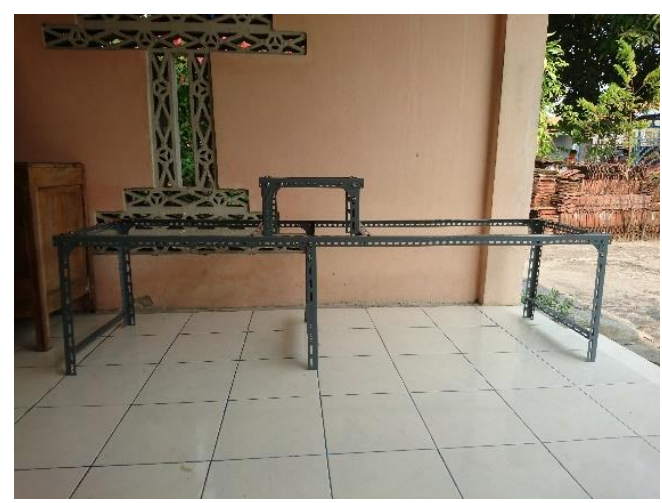

Gambar 10 Kaki-kaki penyangga wind tunnel

g. Pembuatan dudukan dan kaki kaki penyangga motor dengan menggunakan besi siku.

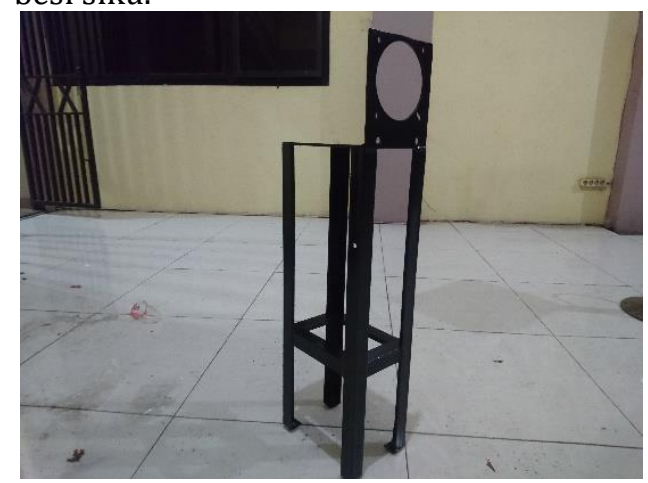

Gambar 11 kaki dan dudukan motor

h. Setelah itu proses selanjutnya adalah pemasangan motor $1 / 2 \mathrm{Hp}$ yang sudah terpasang fan 14 inch di bagian belakang diffuser. 


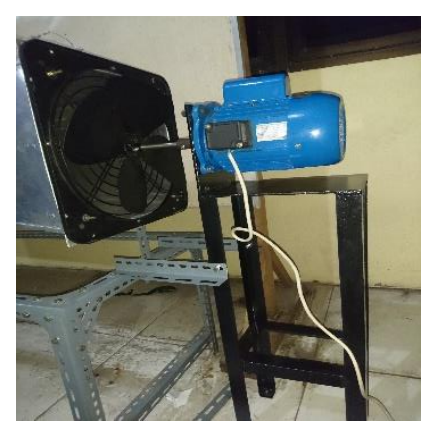

Gambar 12 Pemasangan motor

i. Setelah semua proses diatas selesai dilakukan penyatuan semua bagian wind tunnel yang terdiri dari settling chamber, contraction, test section, diffuser.

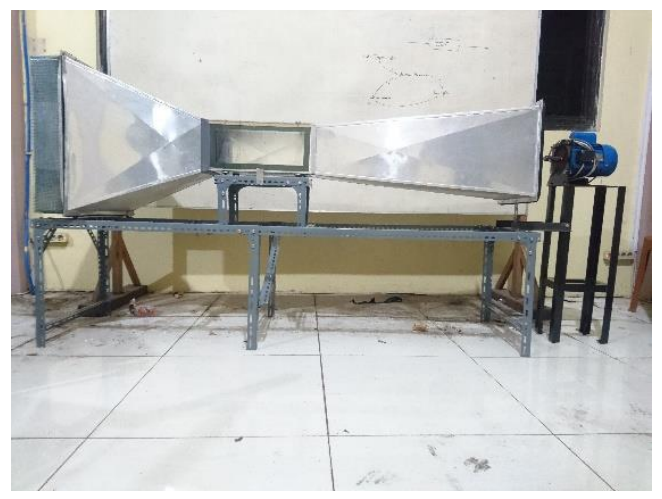

Gambar 13 Wind Tunnel tipe subsonic

\section{PROSES PENGOPRASIAN WIND TUNNEL}

Sebelum pengoprasian wind tunnel pastikan semua alat yang dibutuhkan sudah siap. setelah itu letakkan alat ukur di dalam area test section, setelah itu tutup kembali jangan sampai ada celah karena akan mempengaruhi kecepatan di dalam wind tunnel. Setelah itu nyalakan motor yang sudah terpasang di bagian belakang wind tunnel, tunngu sekitar kurang lebih satu menit, setelah itu lihat alat ukur disitu akan terlihat kecepatan maksimum di dalam area test section.

\section{PENUTUP}

Dari proses rancang bangun wind tunnel tipe subsonic ini menghasilkan wind tunnel skala labolatorium dengan panjang test section $0,452 \mathrm{~m}$, diffuser 0,909m, contraction 0,508m, hanycome $0,096 \mathrm{~m}$, dan wind tunnel yang sudah dibuat dapat bekerja dengan baik.

Adapun saran untuk kedepannya agar lebih baik. Untuk penelitian perhitungan getaran saat pengujian perlu dilakukan untuk mengetahui seberapa besar pengaruh terhadap keseragaman yang terjadi, untuk pemotongan hanycome diusahakan tidak manual, untuk mendapatkan kecepatan yang maximum diusahan tidak ada celah sedikitpun pada setiap sambungan wind tunnel, untuk tahap selanjutnya ada baiknya dilakukan study komparasi terowongan angina ini dengan terowongan angin yang sudah di standarisasi agar dapat mengatahui kelebihan dan kekurangannya sehingga bisa diadakan riview untuk kesempurnaan alat.

\section{DAFTAR PUSTAKA}

Afifah YN (2019). Analysis of Unsteady Magneto Hydro Dynamic ( MHD ) Nano Fluid Flow Past A Sliced Sphere Analysis of Unsteady Magneto Hydro Dynamic ( MHD ) Nano Fluid Flow Past A Sliced Sphere. In: IOP Conference Series: Materials Science and Engineering. Vol 494. ; 2019:012033. doi:10.1088/1757-899X/494/1/012033

Ahmad Marabdi Siregar. 2016. "Rancang Bangun Wind Tunnel Sederhana untuk alat Pendukung Studi Experimental", Teknik Mesin UNIVERSITAS MUHAMMADIYAH SUMATRA UTARA

Bell, J.H., R.D. Metha. 1989. Boundary-Layer Predictions for Small Low Speed Contractions. London. AIAA Journal. http://vonkarman.stanford.edu/tunnel/contra ction paper.pdf

Barlow, Jewel B., William H. Rae. Barlow, Jewel B., William H. Rae, Alan Pope. 1999. LowSpeed Wind Tunnel Testing-3rd ed. New York. John Wiley \& Sons, Inc.

Harold Sherwood Boudreau Iii. 2009. Design, Construction, And Testing of An Open Atmospheric Boundary Layer Wind Tunnel, University Of Florida.

Kotwani, Kailash. 2003. Wind Tunnel Performance Analysis.

http://www.casde.edu/windtunnel.pdf, akses : 16 Januari 2009

Miguel A. González Hernández, Ana I. Moreno López, Artur A. Jarzabek, José M. Perales Perales, Yuliang $\mathrm{Wu}$ and Sun Xiaoxiao. Design Methodology for a Quick and LowCost Wind Tunnel http://dx.doi.org/10.5772/54169 
Nidia Yuniarsih Dan Wowo Rossbandrio. 2015.

"Pengembangan Terowonga Angin

Kecepatan Rendah (Low Speed Wind

Tunnel)", Untuk Tujuan Edukatif Di

Politeknik Negri Batam, Teknik Mesin

Politeknik Negri Batam

Sherwood Boudreau III Harold. 2009. Design, Construction, And Testing Of An Open Atmospheric Boundary Layer Wind Tunnel, University Of Florida 